\title{
Two Cubed Approach in a Collaborative Classroom and the Enhanced Algebra and Social Skills of College Students
}

\author{
Delon A. Ching \\ College of Teacher Education, Laguna State Polytechnic University, Philippines
}

Received June 9, 2020; Revised July 31, 2020; Accepted August 10, 2020

\section{Cite This Paper in the following Citation Styles}

(a): [1] Delon A. Ching , "Two Cubed Approach in a Collaborative Classroom and the Enhanced Algebra and Social Skills of College Students," Universal Journal of Educational Research, Vol. 8, No. 10, pp. 4920 - 4930, 2020. DOI: 10.13189/ujer.2020.081064.

(b): Delon A. Ching (2020). Two Cubed Approach in a Collaborative Classroom and the Enhanced Algebra and Social Skills of College Students. Universal Journal of Educational Research, 8(10), 4920 - 4930.4 DOI: 10.13189/ujer.2020.081064.

Copyright $\subseteq 2020$ by authors, all rights reserved. Authors agree that this article remains permanently open access under the terms of the Creative Commons Attribution License 4.0 International License

Abstract Working in joint effort empowers students' dynamic social connection and helps oversee intellectual and behavioral improvements. This study focused on assessing the effectiveness of the Two Cubed Approach as an introduced Collaborative teaching practice in enhancing the Algebra and the social skills of the students. One group pretest and posttest experimental research design was used to 38 College of Teacher Education first-year Mathematics major students, during the second semester of the academic year 2018-2019. The students experienced working in two cubed collaboration, quartic discussion, paired sharing, and individual verification. Its ultimate goal is to make them become independent learners who mastered the competencies set. The result shows a significant positive increase from pretest to posttest scores in the algebra skills of the respondents, which implies enhanced skills in recalling, simplifying, analyzing, solving, and applying the concepts learned from poor to fair level reached very good to excellent performances. This study also showed that the use of two cubed approaches in the classroom enhanced the social attributes of the learners. They were able to establish good working relationships and shared relevant ideas in accomplishing the tasks provided, leading to a more productive learning experience. The use of two cubed approaches in learning algebraic concepts enhances the students' skill for them to achieve better performances, and its collaborative segments led to a positive view in dealing with their group mates in attaining a high level of social skills.

Keywords Two Cubed Approach, Collaborative Classroom, Algebra Skills, Social Skills

\section{Introduction}

Collaborative approaches in the classroom have become an educational trend in the 21st century [1]-[2]. The necessity of working together on issues and challenges towards academic endeavors is now on its shift. It highlights an individual's effort to collaborative output, from an independent perspective to the community of learners. Working in collaboration encourages students' active social interaction and helps manage cognitive and behavioral developments. Collaborative learning has several reasons that make it useful in the classroom; whenever the students are engaged in the subject matter, mainly the task rather than just watching and listening to their teacher will make them learn the concepts better. Also, students who belong to below-average performance do not give up learning and become more responsible for their learning. This is accounted to their group overall performance. On the other hand, students in the above-average benefits in the learning structure could share what they know and clarify things for their group 
members [3]-[5]. Collaborative learning also considers each member's role in putting themselves in the position of another, which leads to the development of the social skills of the students. Furthermore, the collaborative structure encourages positive learning to construct with proper observation of student's relationships with peers, which lower the negative attributes like loneliness, social anxiety, and stress.

Making students more engaged in Mathematics class for them to learn Algebraic concepts with mastery of the competencies and with secure social connections to their classmates, the use of Collaborative learning approaches is encouraged. With this idea, the researcher innovated a teaching approach that emphasizes the collaborative work of the students. It is the Two Cubed collaborative learning, which includes its thematic task exposed to two cubed collaboration, quartic discussion, paired sharing, and individual verification.

Collaborative learning is framed from the Sociocultural Theory introduced by Vygotsky, which expresses that the fundamental idea of taking in is based on social practice through the Zone of Proximal Development (ZPD) [6]. The purpose of Vygotsky's sociocultural perspectives has an outstanding commitment to social constructivist epistemology underscoring how the learning state of the students helped the learning substance which is imparted to peers. This seems to evoke the possibility that social communication has a critical relationship to one's psychological turn of events. Given the sociocultural viewpoint, learning is a necessary social term and not an individual point of view naturally. This is where the collaboration between people is watched for the achievement of the education and learning process. Social collaboration between individuals from the group's work is an underlying advance towards the improvement of perception. This fills in as the symbolic portrayal that guides people's associations that can't be separated from the social setting built up. In another viewpoint, intellectual capacities are connected with the elements concerning sociocultural.

Moreover, Vygotsky's formative speculations depend on the congruity or solidarity set up behavior and mindfulness. The related practice and mindfulness or the unification of brain and social collaboration are significant portrayals of Vygotsky's formative speculations since it signifies absolutely what establishment human developments. Vygotsky explained the contrasts among biological and sociohistorical types of advancement. He guaranteed that the development of natural concerns reveals with time doesn't prompt improvement structure; however, a different kind of behavior and social cooperation will be made [7].

Collaboration effort in learning is a way of thinking of association and one's experience. At the same time, the individual oneself is liable for their exercises or activities like learning things and offering appreciation to one's thoughts and imparted abilities to peers. At whatever point the individuals from the group meet up to work for an assignment, it recommends coordinated effort in managing others regarding the thoughts shared and being answerable for jobs demonstrating their abilities and different commitments. It was observed in the group that there is a shared initiative and ready to contribute capably for the group's academic success [8]. The establishment set for collaborative learning depends on thinking of an accord reaction through dynamic inclusion and practical activities of each group of individuals. It contrasts with individualized discovering that just one will exceed expectations among groups.

Exposure to group work allows students to enhance different cognitive aspects like critical and analytical thinking, communication skills, and other learning processes. It also acknowledged perspective with respect, techniques, and strategies in problem-solving, and other factors that involve active learning and student learning. The teachers or instructors who shared a part in this innovative practice further develop the students' skills to think critically and analytically while working with group mates. Students who are academically challenged and somewhat discouraged when working individually may feel more relaxed in learning, specifically in dealing with Mathematical problems if they work collaboratively with other students in a group. Somehow, the increase in self-esteem and a higher level of social competence may help students gain a positive view of the school. Furthermore, it is also noted that students may realize the relevance of being exposed to different ways of showing the solutions. It is for the reason that they may accommodate a more straightforward way of arriving to correct answers, which may result in higher capacities of individual work and developments [9].

There are ways on how collaboration among students can be established for them to learn. They may work competing to realize who is "best," work independently moving toward a common goal of the group without tracking what others did, or work with other individuals in the group, giving efforts or contributions learning together as well as their own. Of all the three ways enumerated, competing with one another is the most common. Research shows that most students see school as an environment with a competition where one student compete to do better than the others. This competitive expectation started during the time a student enters schooling and becomes more developed as time goes to school [10].

Students exposed to different innovative learning conditions may not only gain cognitive developments but also learn from shared experiences of their peers. Better opportunities to discuss concepts and exchange of intellectual ideas can be more established when collaborative learning approaches are being used [11]. Collaborative learning makes a group of students who 
struggle together to achieve one unified goal not only for their knowledge but also for others' learning.

Collaborative learning systems, which incorporate social skills education, seem to have beneficial outcomes for students, as reflected in expanded scholarly accomplishment and improved social perspectives and behavior. The overall chief being that students cooperate as a group helps students take in something of significant worth from the agreeable movement. These advantages appear to impact the school's scholarly and social atmosphere, also [12].

Collaborative learning follows this thought as groups cooperate to learn or tackle an issue, with every individual answerable for seeing all angles. The small groups are essential to this procedure since students can both be heard and hear their friends, while in a conventional study classroom setting, students may invest more energy tuning into what the teacher says. Group learning utilizes both objective relationship and asset reliance to guarantee cooperation and correspondence among bunch individuals. Changing the job of the teacher from addressing to encouraging the group helps cultivate this social condition for students to learn through connection [13]. With this guiding principle established in the research, the researcher introduced a collaborative learning approach through Two Cubed and examined its effectiveness in enhancing college students' algebra skills and social skills.

\section{Objectives of the Study}

This research would like to determine the effect of innovative collaborative learning labeled as Two Cubed Approach in enhancing the algebra skills and social skills of college students. Specifically, this aims to:

1. document and analyze the pretest and posttest scores performance of the students exposed to Two Cubed Approach based on the Algebra skills assessment in terms of recalling, simplifying, analyzing, solving, and applying.

2. describe the level of social skills of the students after being exposed to the Two Cubed Approach.

3. find out if there is a significant difference between the pretest and posttest score performance of the students before and after exposure to two cubed approach.

4. find out if there is a significant relationship between the social skills and algebra skills of the student-respondents.

\section{Materials and Methods}

This study assessed the effectiveness of the Two Cubed Approach as an introduced Collaborative teaching practice in enhancing the Algebra and the social skills of the students. One group pretest and posttest experimental research design was used to 38 College of Teacher
Education first-year Mathematics major students, during the second semester of the academic year 2018-2019.

The students experienced working in two cubed collaboration, quartic discussion, paired sharing, and individual verification which its ultimate goal is to make them become independent learners who mastered the competencies set. 5-minute preliminary activities and classroom management were allotted then to be followed by a 10-minute lecture of the teacher. Students will be divided into Two Cubed collaboration groups with a minimum of 8 members. They will collaborate on answering a problem within 5 minutes, ensuring that each member understands the concept. A 5-minute discussion of the groups' answers will take place after. The group will be divided into two groups where they will be exposed to the quartic discussion (two squared groups) of a problem to be given with a minimum of 4 members each exposed to 5-minute group discussion of answers to activity and 5-minute analysis of the solution to be done by the teacher. Each group will be divided into two groups where they will experience paired sharing (two raised by one group) with a minimum of 2 members answering a 5-minute task and discussion will take place after. Lastly, since its assumption is to make students be independent learners, they will solve an assessment in an individual verification process (two raised by zero groups), which will be followed by a 10-minute discussion, generalization, and closing activities by the teacher in the classroom.

Pre-Post Test was used to measure the algebra skills development of respondents, it is a good basis of quantitative data in comparing the students' pretest and posttest scores or their performance which showed a significant difference before and after the use of Two Cubed Approach. The questions constructed in terms of recalling, simplifying, analyzing, solving and applying mathematical concepts as identified in Bloom's Cognitive domain of learning aligned in the competencies set by the teacher. The preparation resulted in a 30 -item examination, where the researcher/ teacher facilitator considers $20 \%$ per Algebra skills.

A 30-item survey questionnaire is to be prepared to assess the social skills of the students. This will measure how students described themselves working with their groupmates during the time they are in their respective groups in the process of Two Cubed Approach. The researcher adopted a questionnaire from the study Lesson in Character Impact Evaluation [14].

\section{Results and Discussion}

Collaborative learning enhances student's cognitive aspect and behavior. To prove this concept the comparison of the pretest and posttest scores of the student-respondents were obtained through the constructed 30-item examination, where the researcher/ teacher facilitator considers 20\% per Algebra skills in terms of recalling, 
simplifying, analyzing, solving and applying mathematical concepts.

The following tables show the performances if the student-respondents in the pretest and posttest in each Algebra skills.

As shown in table 1, students during pretest in the Algebra skills of recalling concepts posted performances rated good to very good, which implies that most of them have good memory recalling the learning concepts and rules in radical expressions. It also means that they have prior knowledge already of the working definitions of concepts in the competency since these were already discussed to them during junior high school. Since they are majoring in Mathematics, there is a need to master all the terms and conditions in radicals to become excellent.

The use of a collaborative approach, specifically the Two Cubed as an introduced practice, helps most students achieve very good to excellent performance in Algebra as shown by their pretest and posttest results in recalling. This means that they are more profound in the terminology definitions and describe roots based on their quantities and qualities. They are very familiar with the terminologies used, which may lead them to analyze other Mathematical problems effectively.

Social components, as experienced by the students during the two-cubed approach, influence what and how students recollect Mathematical ideas that they need to incorporate in answering problems, as the students intelligently fabricate and recover ideas and Mathematical patterns then the memory follows [15]. According to this work from two-cubed collaborations, cooperative benefits for memory execution come about because of being involved in the group and being exposed to more data than an individual may experience alone. Recalling concepts at this stage will be more productive.

Before exposure to the collaborative tasks, the instructor's discussion guides students to recall the working definitions in radicals. Moreover, the repeated analysis and exposure to terminologies expressed in different Mathematical problems made in two cubed collaboration, quartic discussion, and paired sharing groupings highlight the action taken through the help of their co-members in the mastery of recalling concepts. As a working character of the two-cubed approach, it allows students to work from large groups to smaller groups in answering Mathematical problems. Exposure to a larger group in the two-cubed collaboration stage sometimes processes instructing and learning basically in a single direction process. In contrast, the leader and the one with more original ideas share the ideas recalled, while in smaller groups like quartic discussion and paired sharing sessions. They show increasingly engaged students who share recalled ideas/standards. Likewise, smaller groups are profoundly intuitive and empowered further conversation on multiple points [16].

Table 2 reveals that the students obtained fair to good performances in simplifying radical expressions, which means that they have an average level of the skill before they were exposed to the Two Cubed Approach. Most students have their basic competence in simplifying quantities in a radical form, extracting the radicand roots. However, when they were exposed to two cubed collaboration, quartic discussion, and paired sharing groupings, they achieved good to excellent performances in simplifying radical expressions. This means that most of the respondents highly mastered reducing the roots from the radicand to make the expression simpler, making it more readable and solvable.

Table 1. Frequency Distribution of Ratings obtained in Algebra Skills Assessment in terms of Recalling Using Two Cubed Approach

\begin{tabular}{|c|c|c|c|c|c|}
\hline \multirow{2}{*}{ Rating } & \multicolumn{2}{|c|}{ Pretest } & \multicolumn{2}{|c|}{ Posttest } & \multirow{2}{*}{ Interpretation } \\
\cline { 2 - 5 } & $\mathrm{f}$ & $\%$ & $\mathrm{f}$ & $\%$ & \multirow{2}{*}{ Excellent } \\
\hline 95 and above & 6 & 15.79 & 16 & 42.11 & Very Good \\
\hline $90-94$ & 16 & 42.11 & 15 & 39.47 & Good \\
\hline $85-89$ & 11 & 28.95 & 5 & 13.16 & Average \\
\hline $80-84$ & 2 & 5.26 & 2 & 5.26 & Fair \\
\hline $75-79$ & 3 & 7.89 & 0 & 0.00 & Poor \\
\hline 74 and below & 0 & 0.00 & 0 & 0.00 & 100.00 \\
\hline Total & 38 & 100.00 & 38 & & \\
\hline
\end{tabular}

Table 2. Frequency Distribution of Ratings obtained in Algebra Skills Assessment in terms of Simplifying Using Two Cubed Approach

\begin{tabular}{|c|c|c|c|c|c|}
\hline \multirow{2}{*}{ Rating } & \multicolumn{2}{|c|}{ Pretest } & \multicolumn{2}{|c|}{ Posttest } & \multirow{2}{*}{ Interpretation } \\
\cline { 2 - 5 } & $\mathrm{f}$ & $\%$ & $\mathrm{f}$ & $\%$ & Excellent \\
\hline 95 and above & 2 & 5.26 & 16 & 42.11 & Very Good \\
\hline $90-94$ & 6 & 15.79 & 7 & 18.42 & Good \\
\hline $85-89$ & 8 & 21.05 & 10 & 26.32 & Average \\
\hline $80-84$ & 10 & 26.32 & 4 & 10.53 & Fair \\
\hline $75-79$ & 8 & 21.05 & 1 & 2.63 & Poor \\
\hline 74 and below & 4 & 10.53 & 0 & 0.00 & 100.00 \\
\hline Total & 38 & 100.00 & 38 & & \\
\hline
\end{tabular}


As observed by the teacher-in-charge who handles the sessions, some students are very careless of giving their final answers. They thought that once solved, and the derived quantity is already the definitive answer without considering that there is still a need to simplify the solutions. However, upon exposure to the Two Cubed Approach, some co-members validate the final answer first before it will be flashed as the final answer to the teacher. Being in a group as an advantage ensures that there are more minds to think of the Mathematical solution than a solitary person. Working in groups from collaboration to paired sharing has a unique resource of ideas to tap and more data accessible given mathematical foundations' assortment, specifically on simplifying their answers [17].

Focusing on Mathematical structure helps students make associations among concepts, patterns, and portrayals that may seem unique but are quite comparative. With a comprehension of Mathematical structure, students can concentrate on the numerical likenesses of concepts that may sound, by all accounts, to appear as something else, which can improve simplifying their answers before its submission to their teacher [18].

As indicated in table 3 for analyzing as an Algebra skill, the result of the pretest resulted that the students have poor to a fair level, which means that most of them fail to comprehend and examine the details from the questions to evaluate radical expressions fully. This poor to fair level in the pretest that students did not consider determining some important concepts first in radical expressions ensures that they will arrive for the correct response.

Exposure to Two Cubed Approach makes sense in enhancing students' ability to analyze concepts in radical expressions as expressed by their posttest results. The approach may not be that successful, preparing all students reached excellent performance. Still, it makes a notable result of bringing them to become fair to a functional analysis of radical expressions. Minimal numbers from 28 to 5 were observed to perform poorly, indicating that the use of Two Cubed Approach is still effective in enhancing the students' analysis skills.

There are students, in spite of a good comprehension of scientific ideas are conflicting at analyzing Mathematical problems that sometimes drives to miscalculations of the answers. They make mistakes since they misread or convey numbers inaccurately or may compose numerical unmistakably enough or in the right section. These students are struggling with Mathematical analysis, where essential calculation and "right answers" are pushed. Frequently they end up with remedial classes, despite the fact that they may have an elevated level of potential for more significant level numerical reasoning. The five students depicted with a poor level on analyzing Mathematical concepts undergone remedial sessions guided by the teacher to ensure attainment of analyzing standards in Mathematics [19].

Looking at the brighter side where most of the respondents obtained good performances, in each of the grouping sessions such as two cubed collaboration, quartic discussion, and paired sharing, the teacher gives two or more problems that students need to answer within their groups working collaboratively and discuss the process on how they arrive with the correct response. These repeated sessions from 8 members, 4 members, and 2 members help establish examining and making sense of the details or given to effectively solve radical expressions and equations.

Table 3. Frequency Distribution of Ratings obtained in Algebra Skills Assessment in terms of Analyzing Using Two Cubed Approach

\begin{tabular}{|c|c|c|c|c|c|}
\hline \multirow{2}{*}{ Rating } & \multicolumn{2}{|c|}{ Pretest } & \multicolumn{2}{|c|}{ Posttest } & \multirow{2}{*}{ Interpretation } \\
\cline { 2 - 5 } & $\mathrm{f}$ & $\%$ & $\mathrm{f}$ & $\%$ & Excellent \\
\hline 95 and above & 0 & 0.00 & 1 & 2.63 & Very Good \\
\hline $90-94$ & 0 & 0.00 & 2 & 5.26 & Good \\
\hline $85-89$ & 2 & 5.26 & 12 & 31.58 & Average \\
\hline $80-84$ & 1 & 2.63 & 7 & 18.42 & Fair \\
\hline $75-79$ & 7 & 18.42 & 11 & 28.95 & Poor \\
\hline 74 and below & 28 & 73.68 & 5 & 13.16 & 100.00 \\
\hline
\end{tabular}

Table 4. Frequency Distribution of Ratings obtained in Algebra Skills Assessment in terms of Solving Using Two Cubed Approach

\begin{tabular}{|c|c|c|c|c|c|}
\hline \multirow{2}{*}{ Rating } & \multicolumn{2}{|c|}{ Pretest } & \multicolumn{2}{|c|}{ Posttest } & \multirow{2}{*}{ Interpretation } \\
\cline { 2 - 5 } & $\mathrm{f}$ & $\%$ & $\mathrm{f}$ & $\%$ & \multirow{2}{*}{ Excellent } \\
\hline 95 and above & 0 & 0.00 & 10 & 26.32 & Very Good \\
\hline $90-94$ & 2 & 5.26 & 9 & 23.68 & Good \\
\hline $85-89$ & 6 & 15.79 & 10 & 26.32 & Average \\
\hline $80-84$ & 12 & 31.58 & 6 & 15.79 & Fair \\
\hline $75-79$ & 12 & 31.58 & 3 & 7.89 & Poor \\
\hline
\end{tabular}


The results of the pretest in Algebra skills assessment depicted in table 4 for solving indicates that the students have poor to good performances in evaluating and manipulating quantities in radical expressions and equations. This means that some students have moderate prior knowledge of the concepts to be introduced and some did not master the competency in solving such. However, after the exposure to Two Cubed Approach, the posttest revealed that students remarkably got good to excellent performances in Algebra. This indicates that they were able to process their knowledge very well to ensure that proper solutions can be obtained in substituting and evaluating quantities in radical expressions and equations.

The guidance given by those knowledgeable students in the group led them to become successful in generating answers from the problems given by the teacher. The assumption that the strategy can make students become independent solvers were observed as most of the students remarkably enhances their solving skills from poor level to excellent performances. During the time that the students were in Two Cubed collaboration session, those students with an average level of solving Mathematical problems listen carefully to the one who masters the most. When they are already in quartic discussions since four members of the group share ideas and strategic approaches that they can apply in the solutions that they need to elicit. When they reach the paired sharing session, they are more profound in expressing their Mathematical concepts with their partners that they are both responsible to ensure correct solution for them to obtain the correct answer. So that in the individual verification the student himself/ herself is now ready and competent in answering his/her own Mathematical problem which is the result of attaining good to excellent performances in the test.

Despite the fact that students may have discovered the right answers, they may have followed an inappropriate way to deal with their solution; some students may build up the right arrangement solving strategies yet in any case arrive at an inappropriate arrangement because of basic solution errors. In general, understanding the concept or the problem context, foundation of the numerical associations between what is given and what is required, assurance of the tasks to be directed for the proper solution execution, leading the activities and checking of the exactness of the solution that can be characterized as good way or strategy needed to be undertaken [20].

It was noted in table 5 that student's performance in the pretest with regards to applying skills resulted to have poor to a fair level which indicates that most of the students cannot apply fully radical concepts to real-life situations. It means that when problems in radicals are expressed in scenarios and the quantities were needed to be processed, the students are poor performers. However, after being exposed to Two Cubed Approach, their performances elevated that they were able to achieve very well to excellent performances. With this, students have the mastery of the competencies related to radical expressions and equations and were able to understand concepts in order to manipulate the given from work problems in radicals following the correct process of solutions and arriving at the correct response.

The teacher ensures that in every group collaborative task provided in two cubed collaboration, quartic discussion and paired sharing there exists at least one-word problem that students need to answer. They are tasked to work collaboratively processing the details in the situations given in the problem. Student leaders and co-members were observed deliberating closely on the results of their solutions.

By taking care of the concepts that they understand in a certain problem, students figure out how to apply their Mathematical abilities in new manners; they build up a more profound comprehension of Mathematical thoughts and experience the true processes to be undertaken in applying concepts to real perspectives. With progress comes a feeling of accomplishment, even happiness, and perhaps hunger for additional task and Mathematical problems to be solved. Continuous practice under these conditions expands their certainty, develops their applying skills, and will be rewarded later on. By the procedure of customary reflection on their critical thinking exercises, students can save these encounters for life-long learning in applying specific Mathematical concepts to real-world problems [21].

Table 5. Frequency Distribution of Ratings obtained in Algebra Skills Assessment in terms of Applying Using Two Cubed Approach

\begin{tabular}{|c|c|c|c|c|c|}
\hline \multirow{2}{*}{ Rating } & \multicolumn{2}{|c|}{ Pretest } & \multicolumn{2}{c|}{ Posttest } & \multirow{2}{*}{ Interpretation } \\
\cline { 2 - 5 } & $\mathrm{f}$ & $\mathrm{f}$ & $\mathrm{f}$ & $\%$ & Excellent \\
\hline 95 and above & 1 & 2.63 & 7 & 18.42 & Very Good \\
\hline $90-94$ & 0 & 0.00 & 15 & 39.47 & Good \\
\hline $85-89$ & 4 & 10.53 & 5 & 13.16 & Average \\
\hline $80-84$ & 7 & 18.42 & 4 & 10.53 & Fair \\
\hline $75-79$ & 11 & 28.95 & 6 & 15.79 & Poor \\
\hline 74 and below & 15 & 39.47 & 1 & 2.63 & 100.00 \\
\hline
\end{tabular}


Table 6. Perceived Level of Social Skills of the Student-Respondents Exposed to Two Cubed Approach

\begin{tabular}{|c|c|c|c|}
\hline Statement & Mean & SD & VI \\
\hline \multicolumn{4}{|l|}{ Whenever we are in a Two Cubed groupings, I... } \\
\hline 1. can control my temper even if I have conflict with my groupmates & 3.54 & .73 & SA \\
\hline 2. acquaint myself to my groupmates without being told. & 3.07 & .82 & A \\
\hline 3. ask questions regarding task rules & 2.75 & .84 & A \\
\hline 4. negotiate well with my groupmates during conflict & 3.04 & .66 & A \\
\hline 5. react properly during peer pressure. & 3.09 & .70 & A \\
\hline 6. share positive views of myself. & 2.99 & .73 & A \\
\hline 7. encourage my groupmates to join group tasks. & 3.22 & .80 & A \\
\hline 8. use my free time properly. & 3.57 & .51 & SA \\
\hline 9. accomplish homework within time bound. & 3.54 & .60 & SA \\
\hline 10. connect myself to friends effortlessly. & 3.49 & .69 & SA \\
\hline 11. react properly whenever teased. & 3.07 & .72 & A \\
\hline 12. can control my temper in conflict situations with older members. & 3.36 & .66 & SA \\
\hline 13. accept criticism properly. & 2.88 & .72 & A \\
\hline 14. initiate intellectual discussion with groupmates. & 3.38 & .63 & SA \\
\hline 15. use time properly while waiting for help. & 3.30 & .69 & SA \\
\hline 16. contribute appropriately in group tasks. & 3.33 & .61 & SA \\
\hline 17. tell my groupmates directly if they treated some of our co-members not well. & 2.96 & .78 & A \\
\hline 18. acknowledge ideas from groupmates during classroom tasks. & 3.78 & .45 & SA \\
\hline 19. give praises to groupmates. & 3.38 & .58 & SA \\
\hline 20. follow directions of the teacher during group tasks. & 3.78 & .45 & SA \\
\hline 21. use work materials with others. & 3.09 & .80 & A \\
\hline 22. work collaboratively without pressure. & 3.22 & .61 & A \\
\hline 23. help groupmates voluntarily. & 3.28 & .82 & SA \\
\hline 24. participate to classroom tasks or to my groupmates without being told. & 3.07 & .91 & A \\
\hline 25. react properly when pushed or hit unnoticed by my groupmates. & 3.04 & .81 & A \\
\hline 26. disregard distractions from groupmates when doing group tasks. & 3.07 & .68 & A \\
\hline 27. keep group area neat and clean without being told. & 3.41 & .71 & SA \\
\hline 28. follow group leader's instructions. & 3.78 & .45 & SA \\
\hline 29. can make transition easily from one group task to another. & 3.28 & .54 & SA \\
\hline 30. connect with groupmates who are different. & 3.41 & .79 & SA \\
\hline Overall & 3.27 & .35 & SA \\
\hline
\end{tabular}

Legend: 3.26-4.00- Strongly Agree (SA)/ High Level, 2.51-3.25- Agree (A)/ Average Level, 1.76-2.50- Moderately Agree (MA)/ Low Level, 1.00-1.75- Disagree (DA)/ Poor Level

Table 6 shows that most of the respondents strongly agreed in the statements given describing their social skills exposing themselves to Two Cubed Approach having an overall mean of 3.27 and a standard deviation of 0.35 which means that they have a high level of social skills. It means that the use of two cubed approaches in the classroom gives positive views of social attributes and students can establish good working relationships with co-members and share relevant ideas in the accomplishment of the tasks provided leading to a more productive learning experience.

The role of unity is observed to the respondents while they were in their two cubed collaboration, quartic discussion, and paired sharing groupings. As noticed in the table most of the students strongly agreed that each member in the group follow group leader's instruction $(\bar{X}=3.78)$ and acknowledges the ideas from groupmates during classroom tasks $(\bar{X}=3.53)$ which implies a high level of social skills of the students aside from they follow directions of the teacher during group tasks $(\bar{X}=3.78)$. The efforts exerted by each member of agreeing and participating properly without too many questions and acknowledgment of one's ideas help evidently to become successful in learning. Collaborations made with 
co-members with the open-mindedness of accepting positive view may result in a higher level of performance.

It is also noted that the students exposed to the Two Cubed Approach use free time properly $(\bar{X}=3.57)$ to effectively accomplish homework within the time bound $(\bar{X}=3.54)$. This is a manifestation that every student in the class during groupings maximizes time to ensure that all competencies will be clearly understood that helps them be an independent learner.

Learning Mathematical concepts is affected by the internal and external factors of the students. One of the affecting external components is social skill having companions in learning exercises. In present-day learning, the learning is student-focused, so the student's communication is expected to find out about certain essential accuracy in processing students' output. The potential and inspiration of students in learning are relied upon to create great social communication so as to get the most extreme outcomes. Social collaboration is a significant part of learning Mathematics since students get the chance to communicate their own observations and solutions so as to empower a reflection on the information they have. And the experience of the students in the Two Cubed Approach from larger group collaboration to paired sharing helps students to be empowered by social skills as they believed that each one can help in the development of their Mathematical competence [22].

Results of the test of difference in table 7 show that there is a significant positive difference in the pretest and posttest scores of the students before and after using Two Cubed Approach in Algebra teaching and learning process since their $\mathrm{p}$ values posted less than 0.05 level of significance in recalling ( $\mathrm{t}=2.663, \mathrm{p}=0.011)$, simplifying $(\mathrm{t}=6.453, \mathrm{p}=0.000)$, analyzing $(\mathrm{t}=9.003, \mathrm{p}=0.000)$, solving $(\mathrm{t}=9.451, \mathrm{p}=0.000)$ and applying $(\mathrm{t}=8.442, \mathrm{p}=0.000)$ mathematical concepts. This means that after being exposed to Two Cubed Approach they enhance their Algebra skills and were able to show mastery of the competencies set in radical expressions and equations. This also shows that the said approach is effective in making students an independent learner who manifests the skills of recalling, simplifying, analyzing, solving, and applying concepts in Algebra.

After the students were exposed to three groups sessions of two cubed collaborations, quartic discussion and paired sharing, they were able to improve their Algebra skills with results of good to excellent in recalling, average to excellent in simplifying, poor level to good in analyzing, fair to excellent levels in solving and poor to very good performance in applying. This is an indication that Two Cubed approach in a collaborative classroom is effective in enhancing the skills of the students. Academic success can be attained in Mathematics when students experienced to collaborate and work with others [23]-[25]. Sharing of ideas and helping one another in improving the Mathematical skills through large groups and small groups is enjoyable in the attainment of educational objectives [26]-[27],[9]. It is said that through collaborative work in Mathematics instruction helps students in posing inquiries, talking about Mathematical ideas, tuning in, having the obligation of what to realize specifically on the questions given by the teacher, censuring usefully and comprising an environment of numerical learning just like what students experienced in Two Cubed Approach [28]-[29].

Table 7. Test of Difference in the Pretest and Posttest Scores of the Student-Respondents in Algebra Skills Using Two Cubed Approach

\begin{tabular}{|c|c|c|c|c|c|c|}
\hline \multirow{3}{*}{ Skills } & \multicolumn{4}{|c|}{ Paired Differences } & \multirow{3}{*}{$\mathrm{t}$} & \multirow{3}{*}{ Sig. } \\
\hline & \multirow{2}{*}{ Mean } & \multirow{2}{*}{ SD } & \multicolumn{2}{|c|}{$95 \% \mathrm{Cl}$ of the Difference } & & \\
\hline & & & Lower & Upper & & \\
\hline Recalling & 3.87 & 8.95 & .925 & 6.811 & 2.663 & .011 \\
\hline Simplifying & 9.50 & 9.08 & 6.517 & 12.483 & 6.453 & .000 \\
\hline Analyzing & 10.71 & 7.33 & 8.300 & 13.121 & 9.003 & .000 \\
\hline Solving & 10.50 & 6.85 & 8.249 & 12.751 & 9.451 & .000 \\
\hline Applying & 13.00 & 9.49 & 9.880 & 16.120 & 8.442 & .000 \\
\hline
\end{tabular}

$\mathrm{p}<0.05$ - Significant 
Table 8. Test of Relationship between Student's level of Social Skills and their level of Algebra Skills Using Two Cubed Approach

\begin{tabular}{|c|c|c|}
\hline \multirow{2}{*}{$\begin{array}{c}\text { Algebra } \\
\text { Skills }\end{array}$} & \multicolumn{2}{|c|}{ Social Skill } \\
\cline { 2 - 3 } & $\mathrm{R}$ & Sig. \\
\hline Recalling & $.392^{*}$ & .015 \\
\hline Simplifying & $.458^{* *}$ & .004 \\
\hline Analyzing & $.782^{* *}$ & .000 \\
\hline Solving & $.814^{* *}$ & .000 \\
\hline Applying & $.607^{* *}$ & .000 \\
\hline
\end{tabular}

*. Correlation is significant at the 0.05 level (2-tailed)

**. Correlation is significant at the 0.01 level (2-tailed).

As revealed by table 8 , there exist a significant relationship between the level of social and Algebra skills of the student respondents in terms of recalling $\left(\mathrm{r}=.392^{*}\right.$, $\mathrm{p}=0.015)$, simplifying $\left(\mathrm{r}=.458^{* *}, \mathrm{p}=0.004\right)$, analyzing $\left(\mathrm{r}=.782^{* *}, \quad \mathrm{p}=0.000\right)$, solving $\left(\mathrm{r}=.814^{* *}, \mathrm{p}=0.000\right)$, and applying $\left(r=.607^{* *}, p=0.000\right)$. This indicates that the social skills of the students have a positive strong relationship to analyzing, solving and applying. In order to obtain good remarks in analyzing and excellent performances in solving and applying there is a need to ensure that there is a high level of social skills of the students.

On the other hand, the social skills of the students have a positive moderate relationship to recalling and simplifying which denotes that for students to have excellent ratings in recalling concepts and simplifying radical expressions students should be observed to have a high level of social skills. It only shows that the proper implication of the social aspect of the students exposed in the Two Cubed Approach performs better in Algebra. It is supported by research results that students working cooperatively with enhanced social skills accomplish a consolidated better yield than students working independently [30]-[32]. The advantages increment further when students share their reasoning and other Mathematical ideas during the activity. Best practices imposed by one student and another student during collaboration improve both critical thinking and calculated comprehension, without the loss of computational understanding. By furnishing students with a structure for communication or proper way of collaboration to their groupmates which they experienced during two-cubed collaborations and quartic discussion, student can be guided adequately towards filling in as a learning network in which sharing math knowledge stretches out comprehension and prompts more elevated levels of accomplishment [33].

\section{Conclusions and Recommendation}

The results of the study show a significant difference between the pretest and posttest score performance of the students before and after exposure to two cubed approaches which implies that the Algebra skills of the student-respondents were enhanced. Teachers may condition the learning environment of the students in a collaborative classroom equipped with different approaches specifically Two Cubed Approach for it may enhance the skill of the students in algebra and in other subjects as well. The researcher effectively made a helpful learning condition in which most of the class flourished through the introduced collaborative learning. There are a few advantages the researcher found while investigating agreeable learning bunches in for Mathematics future educators. The College students who sometimes feel less competitive in solving problems were increasingly persuaded and occupied with the math exercises whenever allowed the chance to work agreeably with their colleagues. Thus, exposure of the students in two cubed collaborations, quartic discussion, paired sharing and individual verification becomes effective for them to acquire good to excellent performances in Algebra specifically in recalling, simplifying, analyzing, solving and applying Mathematical concepts. The goal of the researcher to make them become independent learners who mastered the competencies set is achieved.

Moreover, there is a significant relationship between the social skills and algebra skills of the student-respondents which indicates a strong positive relationship between the social skills and algebra skills of the respondents in terms of analyzing, solving, and applying and a positive moderate relationship in recalling and simplifying. During the collaborative work of the students, they not only work enhancing their cognitive aspect but they also tend to develop social skills by learning together with group members. This means that the use of Two Cubed Approach may not only highlight the analytic ability of the students but it may also drive to holistic development as well and the enhancement of their learning behaviors. With collaboration and social connection assuming such a basic job in the accomplishment, students will benefit massively from direct guidance around social aptitudes. At the point when students experience issues with collaboration and critical thinking, giving them proper guidance during group work to use in these circumstances will help guarantee more noteworthy achievement of the students. When there is a positive collaboration between one student and another who possesses good social skills will surely attain success in the attainment of Mathematical competencies.

The study also recommends to use the approach to non-majors of Mathematics most likely to those Mathematically challenged students and test whether the significant improvement will happen after and prove that Two Cubed Approach is not only for advanced students but for average and below average as well.

\section{REFERENCES}

[1] Laal, Marjan \& Laal, Mozhgan \& Khattami Kermanshahi, 
Zhina. (2012). 21st Century Learning; Learning in Collaboration. Procedia - Social and Behavioral Sciences. 47. 1696-1701. 10.1016/j.sbspro.2012.06.885.

[2] Child, S., \& Shaw, S. (2015). Collaboration in the 21st century: Implications for assessment. Economics, 21, 2008.

[3] Ahmadpanah, M., Soheili, S., Jahangard, L., Bajoghli, H., Haghighi, M., Holsboer-Trachsler, E., \& Keikhavandi, S. (2014). Cooperative learning improves social skills and knowledge of science topics in pre-adolescent children in Iran. British Journal of Education, Society \& Behavioural Science, 4(8), 1029-1037.

[4] Le, H., Janssen, J., \& Wubbels, T. (2018). Collaborative learning practices: teacher and student perceived obstacles to effective student collaboration. Cambridge Journal of Education, 48(1), 103-122.

[5] Backer, Jeanine M.; Miller, Jaymeson L.; and Timmer, Shannon M.. (2018). The Effects of Collaborative Grouping on Student Engagement in Middle School Students. Retrieved from Sophia, the St. Catherine University repository website: https://sophia.stkate.edu/maed/280

[6] Lin, L. (2015). Exploring collaborative learning: Theoretical and conceptual perspectives. In Investigating Chinese HE EFL Classrooms (pp. 11-28). Springer, Berlin, Heidelberg.

[7] Shabani, K. (2016). Applications of Vygotsky's sociocultural approach for teachers' professional development. Cogent education, 3(1), 1252177.

[8] Laal, M., \& Ghodsi, S. M. (2012). Benefits of collaborative learning. Procedia-social and behavioral sciences, 31, 486-490.

[9] Sofroniou, A., \& Poutos, K. (2016). Investigating the effectiveness of group work in mathematics. Education Sciences, 6(3), 30 .

[10] Singh, Dr. Yash \& Agrawal, Anju. (2011). INTRODUCTION TO CO-OPERATIVE LEARNING. Indian Streams Research Journal ISSN:- 2230-7850. 1.

[11] Lavasani, M. G., Afzali, L., Borhanzadeh, S., Afzali, F., \& Davoodi, M. (2011). The effect of cooperative learning on the social skills of first grade elementary school girls. Procedia-Social and Behavioral Sciences, 15, 1802-1805.

[12] Mercendetti, D. (2010). Connecting Social Skills and Cooperative Learning.

[13] Brame, C.J. and Biel, R. (2015). Setting up and facilitating group work:Using cooperative learning groups effectively. Retrieved [todaysdate] from http://cft.vanderbilt.edu/guides -sub-pages/setting-up-and-facilitating-group-work-using-co operative-learning-groups-effectively/.

[14] Hanson, T., Dietsch, B., \& Zheng, H. (2012). Lessons in Character Impact Evaluation. Final Report. NCEE 2012-4004. National Center for Education Evaluation and Regional Assistance.

[15] Andrews-Todd, Jessica \& Rapp, David. (2015). Benefits, costs, and challenges of collaboration for learning and memory. Translational Issues in Psychological Science. 1. 182-191. 10.1037/tps0000025.

[16] Lama, Dr. Polly \& Kulkarni, Jyoti \& Tamang, Binod \&
Sinha, Pranoti. (2015). The impact and significance of small and large group teaching and learning in medical curriculum. Journal of the Anatomical Society of India. 2. 2349-1604. 10.1016/j.jasi.2018.06.085.

[17] Burke, Alison (2011). Group Work: How to Use Groups Effectively. The Journal of Effective Teaching, Vol. 11, No. 2, 2011, 87-95

[18] U.S. DEPARTMENT OF EDUCATION (2015). Teaching Strategies for Improving Algebra Knowledge in Middle and High School Students. National Center for Education Evaluation and Regional Assistance, Institute of Education Sciences. Retrieved from: https://ies.ed.gov/ncee/wwc/Docs /PracticeGuide/wwc_algebra_040715.pdf

[19] Siniguian, Marlon (2011). Students' Difficulty in Solving Mathematical Problems. Retrieved from: Students Difficulty in Solving Mathematical Problem

[20] Özsoy, G., Kuruyer, H. G., \& Çakıroğlu, A. (2017). Evaluation of students' mathematical problem solving skills in relation to their reading levels. International electronic journal of elementary education, 8(1), 113-132.

[21] Badger, M., Sangwin, C. J., Hawkes, T. O., Burn, R. P., Mason, J., \& Pope, S. (2012). Teaching problem-solving in undergraduate mathematics. Coventry, UK: Coventry University.

[22] Apriliyanto, B \& Saputro, Dewi \& Riyadi, Riyadi. (2018). Student's social interaction in mathematics learning. Journal of Physics: Conference Series. 983. 012130. 10.1088/1742-6596/983/1/012130.

[23] Center for Engineering Learning \& Teaching. (2015). Seattle Central College - Campus Reflection Field Guide Reflective Techniques to Encourage Student Learning: Background and Examples. (1st ed.). Seattle, WA

[24] Gebreyohannes, Haftamu Menker. (2017). Effectiveness of Collaborative Learning Approach in Teaching Mathematics". International Journal of Mathematics Trends and Technology (IJMTT). Volume 50 Number 3. 171. 10.14445/22315373/IJMTT-V50P528.

[25] De Corte, Erik \& Verschaffel, Lieven \& Lowyck, Joost \& Dhert, Stijn \& Vandeput, Luc. (2002). Collaborative learning of mathematics. 10.1007/978-0-387-35615-0_7.

[26] Saiyad, Shaista \& Mishra, Sushant \& George, Christina \& Kaur, Gurleen. (2018). Teaching and Learning through Large and Small Groups. 8. S24-29.

[27] Benders, David and Craft, Tracy (2016) "The Effect of Flexible Small Groups on Math Achievement in First Grade," Networks: An Online Journal for Teacher Research: Vol. 18: Iss. 1. https://dx.doi.org/10.4148/2470-6353.1022

[28] Koçak, Z. F., Bozan, R., \& Işık, Ö. (2009). The importance of group work in mathematics. Procedia-Social and Behavioral Sciences, 1(1), 2363-2365.

[29] Shafiuddin, Mohammed. (2010). Cooperative Learning Approach in Learning Mathematics. 589-595.

[30] Samuelsson, J. (2010). The Effect Of Peer Collaboration On Children's Arithmetic And Self-Regulated Learning Skills. Necatibey Faculty of Education Electronic Journal of Science \& Mathematics Education, 4(2). 
[31] Di Fatta, J., Garcia, S., \& Gorman, S. (2009). Increasing Student Learning in Mathematics with the Use of Collaborative Teaching Strategies. Online Submission.

[32] Moghaddam, A., Sarkar Arani, M. R., \& Kuno, H. (2015). A collaborative inquiry to promote pedagogical knowledge of mathematics in practice. Issues in Educational Research, 25(2), 170-186.

[33] Bruce, C. D. (2007). Student interaction in the math classroom stealing ideas or building understanding. 